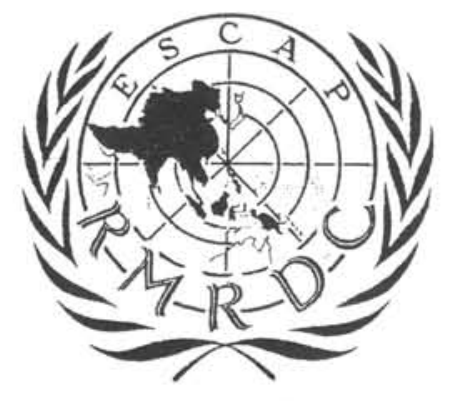

\title{
A UNITED NATIONS ADVISORY CENTRE FOR GEOLOGY IN SOUTHEAST ASIA
}

by

John V. Hepworth

The Regional Mineral Resources Development Centre (RMRDC), a UN establishment based in Bandung, Indonesia, provides the whole ESCAP region with a readily-tapped source of advice and expertise. Since its inception in 1973 some 200 missions have been carried out for member countries in a wide range of geological fields. This article is a brief survey of the recent activities of the Centre.

\section{Background}

It is difficult to talk of United Nations activities without uttering strings of acronyms. Some explanations are necessary at the outset. ESCAP is the Economic and Social Commission for Asia and the Pacific, and is the regional headquarters of the United Nations located in Bangkok. The Natural Resources Division of ESCAP has a number of semidependent children living away from home: the Southeast Asian Tin Research and Development Centre (SEATRAD), situated in Ipoh, Malaysia; CCOP, which is concerned with offshore hydrocarbon and mineral prospecting, and is housed in another part of Bangkok; CCOP/SOPAC, a similar organization based in Fiji; and RMRDC located in Bandung, Indonesia.

When RMRDC was formed in Southeast Asia in 1973, the idea of establishing an intergovernmental body of geoscience consultants in the region was a bold and innovative one. This was because at that time the common assumption was that any center of technical and scientific excellence must naturally be situated in the North (or "West" as it was known) and secondly, that there would be a valuable store of knowledge and experience to be tapped if a group of senior geoscientists could be persuaded to come and work at an institution conveniently placed in the middle of the developing world.

Today the first idea seems less surprising, since fewer people believe that "West is Best". The second idea, that there are people of long experience and high calibre who might be willing to abandon senior administrative positions for a consultant role in the South holds good and has contributed much to the success of RMRDC.

Bandung is a city of 1.5 million people with numerous universities and scientific institutions and five of the main divisions of the Indonesian Directorate-General of Mines. Four of these have taken the place of the old Geological Survey of Indonesia and the fifth is the Mineral Technology Development Centre (MTDC) which provides offices and facilities for RMRDC.

The strangely-shaped tower in which RMRDC resides commands splendid views across Bandung city and its old lake-bed plain surrounded by volcanic mountains. Bandung's own active volcano, Tangkuban Perahu, stands just north of the city but at the time of writing, successive layers of volcanic dust from its relative along the arc, Gunung Galunggung, 60 $\mathrm{km}$ away, were being sporadically deposited over Bandung. Over the past two months this comparatively small volcano has already dispossessed some 40000 people from their homes.

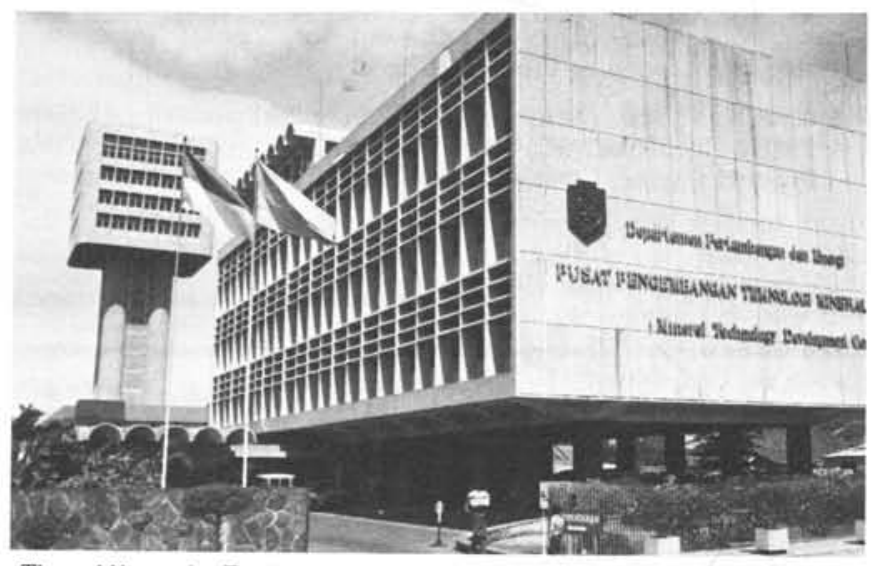

The Mineral Technology Development Centre (MTDC) in Bandung. The RMRDC is located in the tower.

\section{The Operations}

RMRDC comprises a small body of advisors in the earth sciences whose services are available free on request to all geological surveys and similar governmental organizations in the 36 countries of the ESCAP region. Missions, which may take from a few days to a couple of weeks or months, have been undertaken in 22 countries (see map). Costs, including salaries, accommodation, travel and allowances, are paid by the countries donating the specialists to RMRDC. The coordinator and part of the support staff are supplied by the UN.

Donor countries which have supported RMRDC by seconding specialists are Japan, West Germany, the Netherlands, France, Finland, U.K. and one developing country, South Korea. Others are expected soon from India. Japan has been a strong supporter and West Germany has maintained a series of senior hydrogeologists from the beginning.

Local running costs are met by the regional member countries, that is, those for whom the service is run, but even so there is a continuous state of near insolvency, despite recurrent appeals. Indonesia, through its generous provision of both premises and funds, bears a notably high proportion of the costs for RMRDC. 


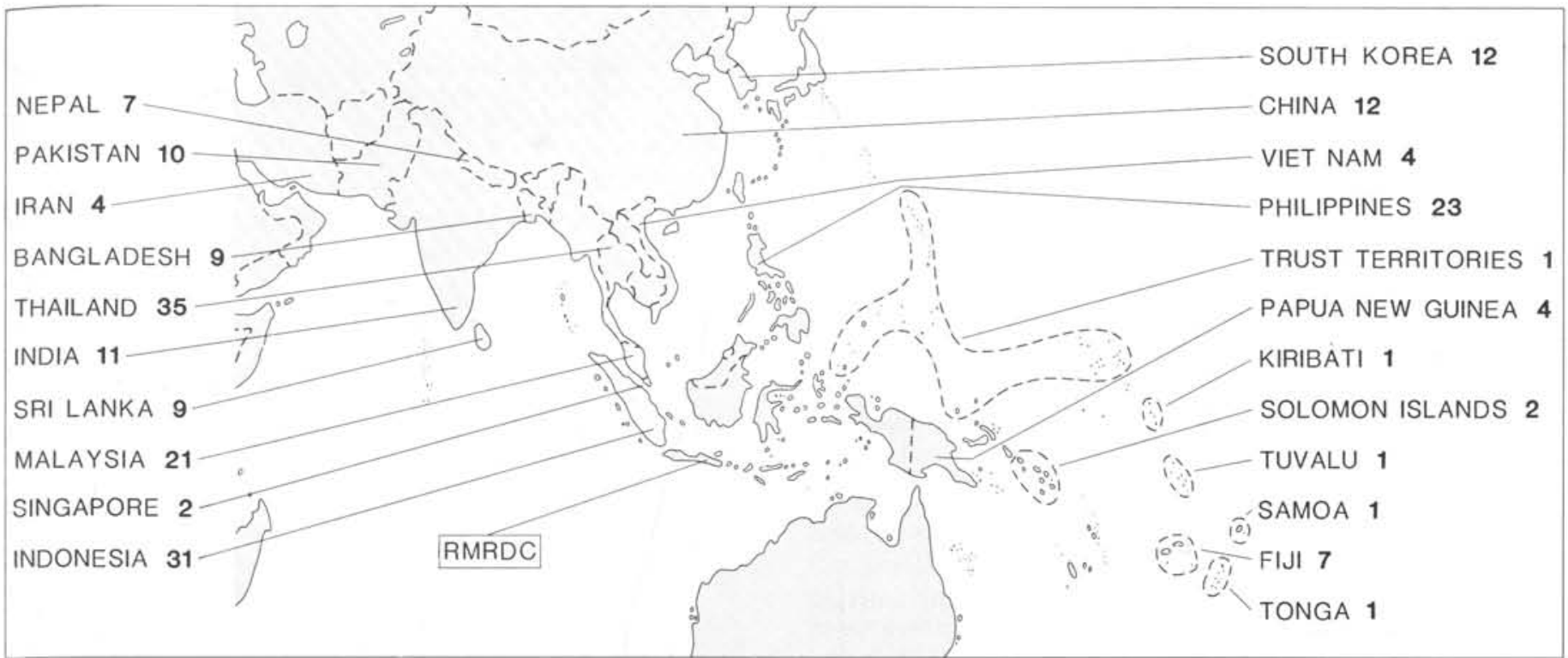

Map of Asia and the Pacific showing the number of RMRDC missions that have been undertaken in 22 countries of the 36-country ESCAP region. Dashed lines around Pacific islands do not indicate national boundaries.

Since its inception in 1973, 195 missions have been carried out by 15 specialists and 167 reports have been issued, mainly indexed under the headings hydrogeology, geochemistry, economic geology, field geology, mining geology, geophysics, mining development and general reports.

Most of the missions are purely advisory and consist of onsite investigations of the problem and suggested solutions in the light of the specialist's experience and expertise. A confidential report to the client follows. On some missions, RMRDC staff participate in the project, for example, in geophysical field work, in the chemical laboratory, or in prospecting for particular minerals.

Some examples of the kind of work which the RMRDC specialists have been doing in the past two years include:

- Shiro Ito (Japan) made recommendations on current anallytical methods for tin and others, and on establishing pathfinders for geochemical prospecting in Bangka and Belitung Islands, Indonesia.

- Klause Krampe (F.R.G.) held discussions and lectures on the regional assessment of groundwater and on the principles for compiling groundwater maps in China.

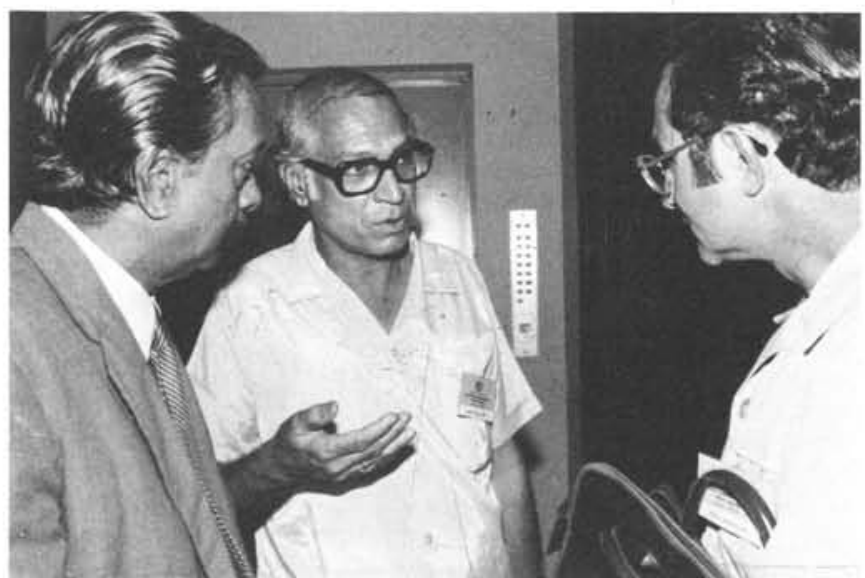

D.J.A.C. Hapuarachchi (Sri Lanka), S.F. Bari (Bangladesh) and $J$. Herakovich (UNESCO) in discussion at the 1981 RMRDC Workshop on Geoscience Information: Practical Applications.
- Herman Stigzelius (Finland), among other topics, advised on the development of graphite mining in Sri Lanka, coal mining in Korea, transport systems in the Ombilin coal field in Sumatra, the advisability of sinking a new shaft in the Indian copper complex, environmental impact of mining in Fiji and tin mining in Thailand, the training requirements of technical personnel in India, and deep mining methods in the Kolar Gold Field. He also investigated gem mining in Nepal, and the applicability of small-scale mining in Vietnam.

Sahng-yup Kim (South Korea) investigated the copper prospects in Panay Island, Philippines, antimony mineralization in Sabah and Sarawak, Malaysia, iron/copper occurrences in Sri Lanka, and also worked in Bangladesh.

- Jacques Becker (France) investigated perlite deposits in Java, made general recommendations regarding the perlite potential of the volcanic regions, and detailed recommendations on the exploitation of marble in Fiji.

- Shun-ichi Sano (Japan) worked in China on experimental VLF-EM surveys and their applicability to karst regions. He has also written a manual on the interpretation of gravity and magnetic data by programmable calculator, and has organized the rock magnetism project which is investigating the tin granite belt of Malaysia and Thailand.

- Naoyuki Ando (Japan) has given advice on analytical techniques and data interpretation related to petroleum geochemistry in China, and on geochemical methods of geothermal exploration in Korea.

- John Hepworth (U.K.) has made recommendations for establishing a Coal Information Service and Database, and advised on information systems in Thailand as well as other countries. He edits RMRDC internal reports and publications.

- Wolfgang Grimmelman (F.R.G.) has started his hydrogeological consulting with a visit to Singapore, to be followed shortly by missions to Vanuatu, Kiribati and Palau.

- The co-ordinator, Pontus Ljunggren (Sweden), in addition to guiding the course of the Project after about 20 years of UNDP senior appointments, has made various economic and statistical analyses in relation to mineral exploration and development in the developing countries. 
It is anticipated that three coal specialists from India will be joining RMRDC to support the Regional Energy Development Programme. A groundwater geophysicist and an economic geologist from West Germany are also expected to arrive in Bandung soon.

\section{Workshops}

In addition to advisory missions RMRDC has held three workshops to date: Decision Variables in Mining, Geoscience Information, and Tungsten Geology. The latter was held in China in October 1981 in collaboration with the Ministry of Geology of the People's Republic. Eight well-known international tungsten experts were invited from the U.S.A., U.K., Australia, Canada, Japan and Sweden together with 15 geologists from the ESCAP developing countries. There were some 47 Chinese participants including academics and government geologists who submitted 28 , out of the total of 48 papers now being edited for publication in Chinese and English by the Chinese Ministry of Geology and RMRDC.

Two more workshops will be held in late 1982, one entitled "The Importance of Mining in Industrial Development" and the other on "Biogeochemical Prospecting in Tropical Rainforest Environments". The latter will discuss the results of a UNDP Swedish/Indonesian project in Sumatra which was designed to test newly-developed methods.

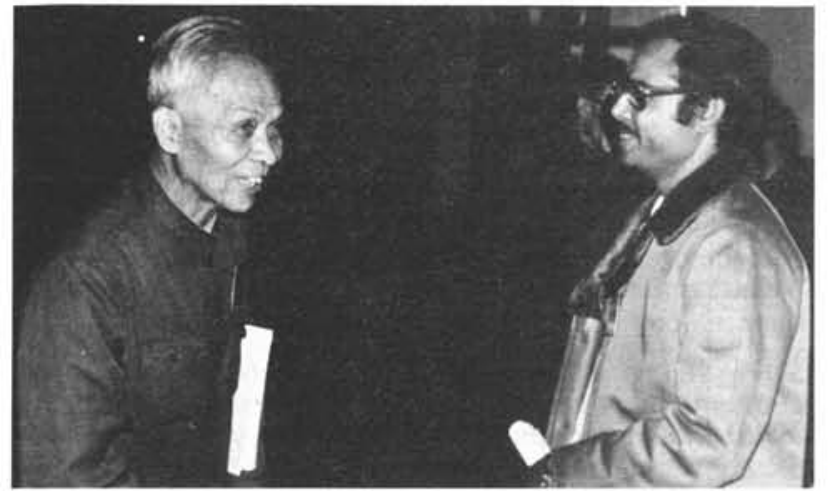

Symposium on Tungsten Geology, held in Jiangxi Province, China, in October, 1981. Deputy Minister Cheng Yuqi (who made important studies in metamorphism and granitization prior to the Second World War as a student of H.H. Read) talks with A.K. Mukhopadhyay, India.

\section{Newsletter and Information Service}

To keep the region informed of its activities, the Centre produces its own Newsletter. RMRDC has recently decided to establish a Coal Information Service as part of the UN Regional Energy Development Program. This will be center- ed around a bibliographic database and will include a service for dissemination of information. When the coal service is working, or at least in good shape, it will be handed over to a regional organization to run as RMRDC is not designed to operate large continuing projects.

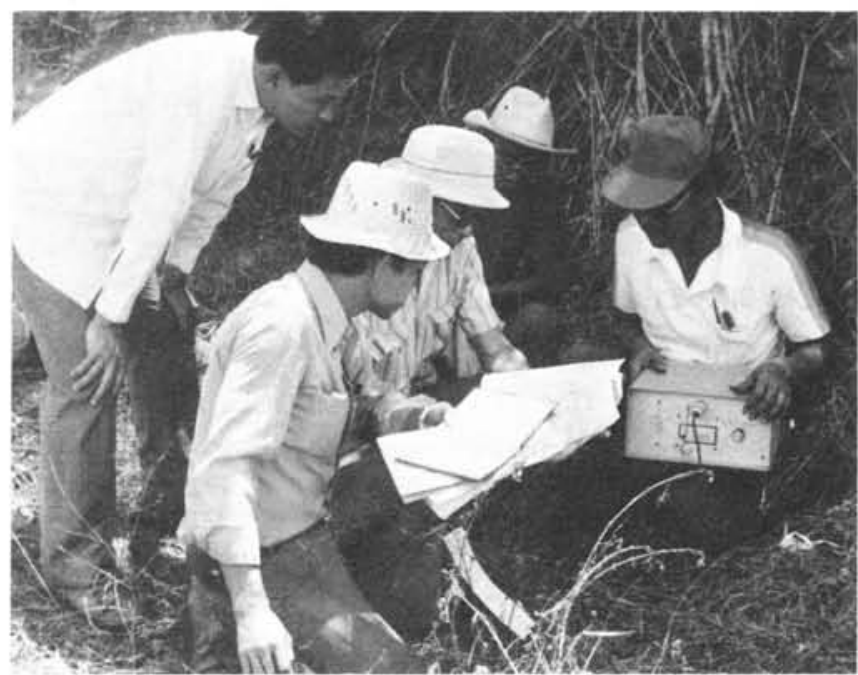

Geologists from Japan, Malaysia, Thailand and Indonesia working with susceptibility meter at Songkla, Thailand, as part of the RMRDC Rock Magnetism Project.

\section{Assessment}

It is clear from RMRDC's experience that there is a need for readily available geoscience consultancy in the region. Most member countries suffer from some deficiency in expertise, and a few are still in the beginner's class.

Administrators of ten overlook the fact that science and technology are not static but continually advancing and that professionals, whether from the North or the South, must remain aware of new developments. This is especially true in the ESCAP region where, with notable exceptions such as the GEOSEA meetings, there is a dearth of learned and professional society activity. The RMRDC workshops, which are always international in composition (usually about 10 nations take part) undoubtedly do something to make good this lack.

There is little client response, however, on which to base an assessment of RMRDC. Perhaps when the local Survey has said "goodbye" to the consultant, they may remark that they could have done just the same thing themselves if they only had the time, and if they had thought of it. However, 195 missions undertaken in 22 countries have obviously left some impact; they certainly demonstrate continuing interest!

\section{ABOUT THE AUTHOR:}

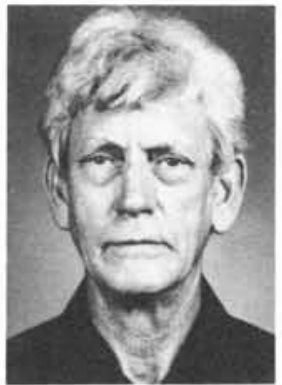

As a survey and research geologist, Dr. John Hepworth applied photogeological techniques to the study of Precambrian tectonics in several parts of Africa. He later became Director of the Geological Survey of Botswana, then Regional Geologist, Asia, for the Institute of Geological Sciences (U.K.). Having generated and consumed geoscience information for many years he was well qualified for his current position as Editor and Information Specialist at RMRDC, Jalan Jenderal Sudirman 623, Bandung, Indonesia. 